\title{
Use of Dramatization to Teach Cardiac Cycle Physiology to Medical Students
}

\author{
Ehsan Dowlati ${ }^{1}$, David W. Musick ${ }^{2}$, Lin Zhang ${ }^{3}$, Katherine Thornton ${ }^{3}$, Helena Carvalho ${ }^{4}$ \\ ${ }^{1}$ VTCSOM, USA \\ ${ }^{2}$ Assistant Dean, Faculty Development and Professor, Internal Medicine, Virginia Tech Carilion School of Medicine, \\ USA \\ ${ }^{3}$ Department of Statistics, Virginia Tech, USA \\ ${ }^{4}$ Biomedical Sciences Department, Virginia Tech Carilion School of Medicine, USA \\ Correspondence: Helena Carvalho, Biomedical Sciences Department, Virginia Tech Carilion School of Medicine, USA.
}

Received: May 12, 2016 Accepted: June 7, $2016 \quad$ Online Published: June 22, 2016

doi:10.11114/jets.v4i9.1603 URL: http://dx.doi.org/10.11114/jets.v4i9.1603

\begin{abstract}
Part of the educator's mission is to develop new methodologies that promote active learning. This study examines the use of dramatization of the cardiac cycle in medical school. Two groups ( $\mathrm{n}=42,21$ each) of first-year medical students participated. Group A was initially taught through dramatization alone, while Group B was taught through lecture followed by dramatization. Students completed a 13-item assessment (pretest and posttest) designed to measure knowledge of the cardiac system immediately before and after participating in the dramatization activity. Six months later students completed a third posttest assessment (follow-up) to assess their retention of cardiac cycle content. Students also rated their prior knowledge of general physiology and their confidence level in learning the material presented. Students in groups A and B scored at the same approximate level on the initial pretest (57\% and $61 \%$ respectively, $\mathrm{p}=0.53)$. Scores for both groups increased significantly on the immediate posttest compared to pretest $(\mathrm{p}<0.0001)$. Both groups scored equally well on the immediate posttest ( $88 \%$ and $89 \%$ respectively, $\mathrm{p}=0.48)$, even though Group A had been taught the content based on dramatization alone. Both groups subsequently scored equally well on the six-month follow-up assessment ( $\mathrm{p}<0.0001)$. Levels of self-reported confidence in knowledge also increased in both groups $(\mathrm{p}<0.05)$. This interactive teaching method increases student confidence in their knowledge and promotes learning in the short term equally well when compared to more traditional teaching methods. Implications for further research on dramatization as a teaching method are explored.
\end{abstract}

Keywords: active learning, interactive teaching, medical education, simulation

\section{Introduction}

Teaching in higher education can take many forms. Most traditionally it involves a classroom lecture with one teacher and many students sitting in rows of desks and passively listening to a PowerPoint presentation, chalkboard talks, or seminars. The importance of modified lectures and pursuit of other forms of teaching innovation is to provide a variety of ways to help students retain the vast knowledge that is required in higher education (Michael, Modell, McFarland, \& Cliff, 2009). Such innovation also attends to students' preference for multiple learning styles and activities in the classroom. Use of a questionnaire that defines different learning styles (VARK: visual, auditory, reading/writing, and kinesthetic) showed that first year medical students (Lujan \& DiCarlo, 2006a), nursing students (Alkhasawneh, 2013) and dental students (N. Shenoy, K.A. Shenoy, \& U, 2013) prefer multimodal methodologies for learning. This manuscript aims to inspire other educators to search for new styles of teaching that respond to their students' needs and convey information in a way that promotes life-long learning.

Looking specifically at the medical curriculum, where there is a vast amount of content that students must master, it is even more important to determine the best method of learning for students. Although it can be important to cover a wide range of material in medical education, it is essential to consider that not everything taught is actually learned (Carvalho, 2009; Lujan \& DiCarlo, 2006b). In traditional teaching, including some types of laboratory settings and lectures where the environment is passive in nature, students are often led to accept the information provided to them without reflection 
(Carvalho, 2009). The teacher assumes all responsibility in relaying the information to students but notes are just transferred from teacher to students without students having the opportunity to reflect on or understand the material (DiCarlo, 2009). The outcome, many times, is rote memorization of the facts which only lasts until the exams. In many institutions the traditional lecture continues to be the most used method, despite evidence showing that students who are taught primarily by traditional lecture have higher failure rates in science, engineering, and mathematics (Freeman et al., 2014). When provided with the opportunity to engage in active learning exercises, students assume responsibility for the material to be learned and are more likely to be able to apply that knowledge (Carvalho \& West, 2011).

In active learning, the teaching is student-centered and students participate in physical or mental tasks that engage them in an interactive activity and take advantage of multimodal strategies of teaching (Miller, McNear, \& Metz, 2013). Examples of active learning in the classroom include interspersing cooperative activities within traditional lectures to keep students engaged (Cavanagh, 2011), using online modules and tutorials that can be watched before class (Prunuske, Batzli, Howell, \& Miller, 2012), hands-on methods (Breckler \& Yu, 2011), computer animations (Lilienfield \& Broering, 1994), and manipulatives (Giffen \& Carvalho, 2015). When students are actively engaged, they are more likely to remember the actual learning experience and retain the information. They tend to be less confused about the material as well (DiCarlo, 2009). Active learning through dramatization is a method that may lead to better learning of the concepts of physiology because it pushes students to understand and retain content rather than to simply memorize it.

Our study focused on an innovative teaching methodology that used dramatization to physically and mentally involve students and by its nature increases motivation and student engagement. The use of dramatization increases alertness by providing students with a specific role and keeping them engaged throughout the activity. LePard used dramatic activities in class to demonstrate other areas of physiology such as motility of the gastrointestinal tract (LePard, 2005); in this study, students mimicked slow waves and phasic contractions to learn concepts that could not be readily or easily understood by simple lecture. In another study, Montrezor showed how creative ways were used to learn synaptic physiology. One group of students developed a learning method through acting and role-playing to better understand the complexities of the nervous system (Montrezor, 2014).

The goal of this study was to evaluate the effectiveness of an innovative teaching methodology for medical education. We designed an active, student-centered learning method that combined dramatization and student engagement to teach cardiac cycle physiology. We hypothesized that the use of dramatization as a teaching tool would improve learning of the material, increase student knowledge level (regardless of previous exposure to the material), increase confidence and satisfaction, and aid in long-term retention of knowledge.

\section{Methods}

\subsection{Subjects}

The Virginia Tech Institutional Review Board approved this research study. Participants included 42 first-year medical students at the Virginia Tech Carilion School of Medicine (VTCSOM). Consented students were asked to participate in the study during the first week of their cardiovascular block, which takes place during the fall of the first year of medical school. All students agreed to participate, and created a tracking ID number based on their birth month and day. The study used a controlled crossover design wherein students were randomly divided into two groups of 21 each (Table I). The instruction for all students was based on two methods of content delivery: lecture and participation in dramatization. Content to the two groups was delivered during two learning sessions occurring during the same week. However, the order in which the two groups received all components of instruction was varied. Group A was initially taught the cardiac cycle through dramatization alone, while Group B was taught through lecture followed by dramatization. The following day students in Group A completed the same learning activities as students in Group B to ensure that all students experienced identical content delivery.

Table 1. Study Design

\begin{tabular}{ll}
\hline GROUP A & GROUP B \\
\hline PRETEST SURVEY* & LECTURE \\
DRAMATIZATION & PRETEST SURVEY* \\
POSTTEST SURVEY* & DRAMATIZATION \\
LECTURE & POSTTEST SURVEY* \\
SIX MONTH FOLLOW-UP SURVEY* & SIX MONTH FOLLOW-UP SURVEY*
\end{tabular}

Sequence of activities for groups A and B. All groups received the same instruction but in difference sequence. *Point in time for data collection 


\subsection{Knowledge Assessments and Ratings of Confidence}

Each student completed a 13-item assessment designed to measure knowledge of the cardiac system. The assessment questions encompassed major aspects of cardiac cycle dynamics, including electrical activity, mechanical activity, neurotransmitters, receptor sites, heart sounds and changes observed with exercise. Students were assured that this assessment would not be graded, and that their participation in the research would have no impact on their final course grade. Students in Group A completed the pretest and posttest assessments immediately before and after participating in the dramatization activity and prior to having a lecture. Students in Group B completed the pretest assessment after participating in a lecture but before participating in the dramatization activity; after the dramatization activity, they completed the posttest assessment. Six months later, all students completed a third assessment (follow-up) to determine their retention of cardiac cycle content from the course.

At the time of the three pre- and posttest assessments, students were also asked to rate their previous knowledge of general physiology and to rate their confidence level in learning the material presented (insufficient, okay, good, very good, excellent). They were also asked to provide feedback on the learning activities, and to provide demographic information (age, sex, highest degree obtained).

\subsection{Statistical Analysis}

Participants' performance was evaluated at the total score level, questions were analyzed individually and confidence levels were also assessed for all participants. To check if there was a difference between the scores of the two groups, we used the Wilcoxon rank sum test to compare the scores of the two groups for pretest, immediate posttest, and follow-up assessments respectively. For item mean comparisons, we compared items within each group for all three pretest and posttest surveys, also within both groups across the three surveys. We used the linear mixed model with unstructured covariance structure to detect if there were any statistically significant differences of the average scores among pretest, posttest, and follow-up assessments. We considered the test type as fixed effect, and participant as random effect. We used the same approaches to investigate confidence level data. We used the logistic mixed effect model to model the probability of giving the correct answer to each question respectively. We also examined the association between individual assessment items and student confidence levels using Pearson and point-biserial correlation procedures. All $\mathrm{p}$ values of $<0.05$ were considered statistically significant at the $95 \%$ confidence level.

\subsection{Dramatization}

During the dramatization the instructor and an assistant facilitated the role-playing. Each student acted as one cell or component mimicking the heart chamber. These included: myocytes, sinoatrial node, atrioventricular node, valve leaflets, red blood cells, or neurotransmitters (norepinephrine or acetylcholine) that symbolized the action of the autonomic nervous system (ANS). The students' respective roles and receptors (M1 or $\beta 1$ ) were noted by signs on their chest or back. Students were then positioned into a figure ' 8 ' shape to make up two chambers of the heart, an atrium and a ventricle (Figure 1A). They then started to act out a functioning heart. To mimic heart cell depolarization, the students lifted their hands simulating the occurrence of the electrical event that preceded the contraction (Figure 1B), which was demonstrated as they moved forward (representing the mechanical event). As the different chambers of the heart contracted, the students moved inward and the "blood," which was also denoted by a few students within the chamber, moved their course from atrium to ventricle. As the blood filled the ventricle, it created a force for the atrio-ventricular valves to close simulating a "heart sound" demonstrated by a clap of the hands between the students representing the leaflets of the valve.

During the dramatization, students participated in a variety of staged scenarios that allowed a broad spectrum of concepts to be taught. For example, scenarios of increased sympathetic or parasympathetic activity were demonstrated as students acting as norepinephrine or acetylcholine would bind to the appropriate receptors on the heart cells. This required students to change the force and frequency in which they moved as a group demonstrating concepts of inotropy and chronotropy. Specifically, we emphasized changes in the cardiac response during exercise since the authors identified it as a difficult topic for students to learn (Carvalho, 2009). 


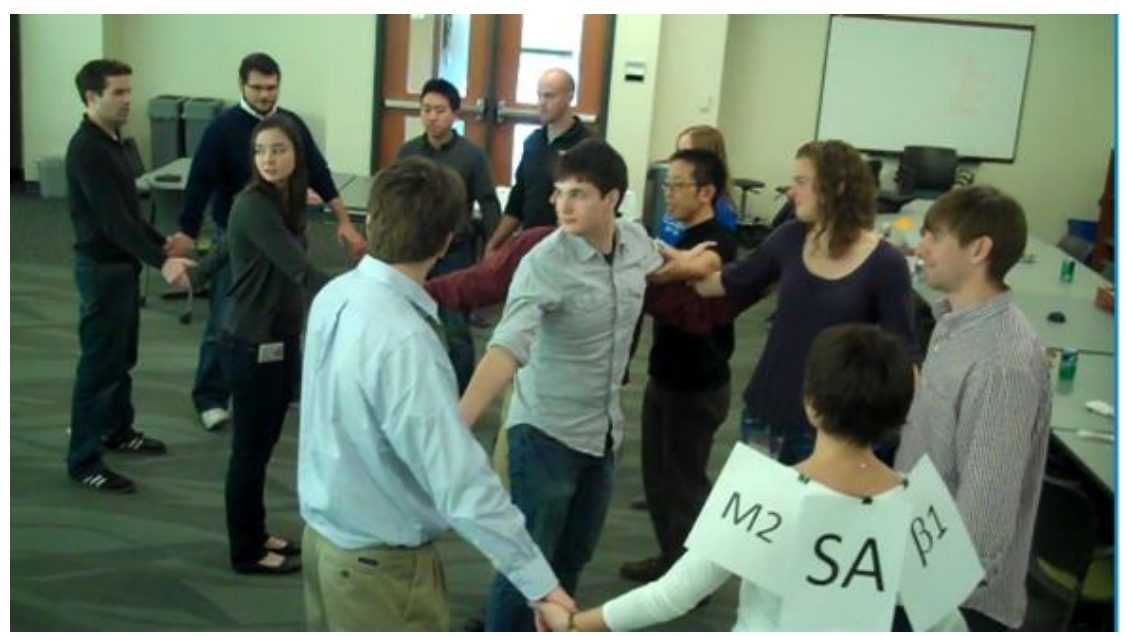

Figure 1a. Students forming figure 8 to represent right or left side of the heart ( 1 atrium and 1 ventricle). In this picture the muscarinic receptor (M2) and beta receptors $(\beta 1)$ are represented only at sinoatrial node (SA)

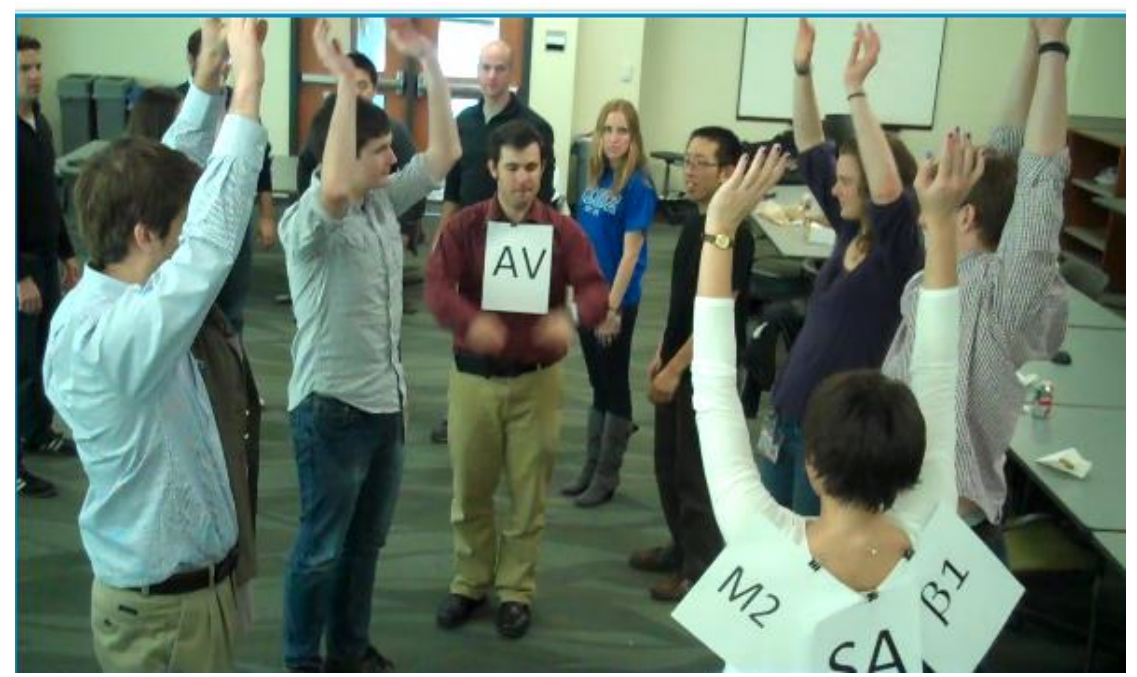

Figure 1b. Students lift their hands in the atrium to represent atrium depolarization. Note the atrium-ventricular node (AV) presents a delay to depolarize and the ventricle cells have not depolarized yet, depicting the atrium depolarization occurring before the ventricle due to AV delay

Note: Volunteer's students in the picture were not participants in the same study presented here.

\section{Results}

Students in both groups reported prior experience in learning physiology, with Group A students reporting slightly less prior experience (76\%) than Group B students (90\%). Regarding other demographic characteristics, the two groups were highly similar (Table 2).

Table 2. Personal profile of both groups

\begin{tabular}{llll}
\hline & Group A & Group B & All \\
\hline $\begin{array}{c}\text { Experience } \\
\text { Prior experience }\end{array}$ & $16(76 \%)$ & $19(90 \%)$ & $35(83 \%)$ \\
$\quad \begin{array}{l}\text { Inexperienced } \\
\text { Gender }\end{array}$ & $5(24 \%)$ & $2(10 \%)$ & $7(17 \%)$ \\
$\quad$ Male & $11(52 \%)$ & $11(52 \%)$ & $22(52 \%)$ \\
$\quad$ Female & $10(48 \%)$ & $10(48 \%)$ & $20(48 \%)$ \\
\hline Age $\quad \begin{array}{l}\text { Average age } \\
\text { Age range }\end{array}$ & 24 & 24 & 24 \\
Degree & $21-32$ & $22-30$ & $21-32$ \\
$\quad$ BS/BA & $16(76 \%)$ & $17(81 \%)$ & $33(79 \%)$ \\
MS or PhD & $5(24 \%)$ & $4(19 \%)$ & $9(21 \%)$ \\
\hline
\end{tabular}




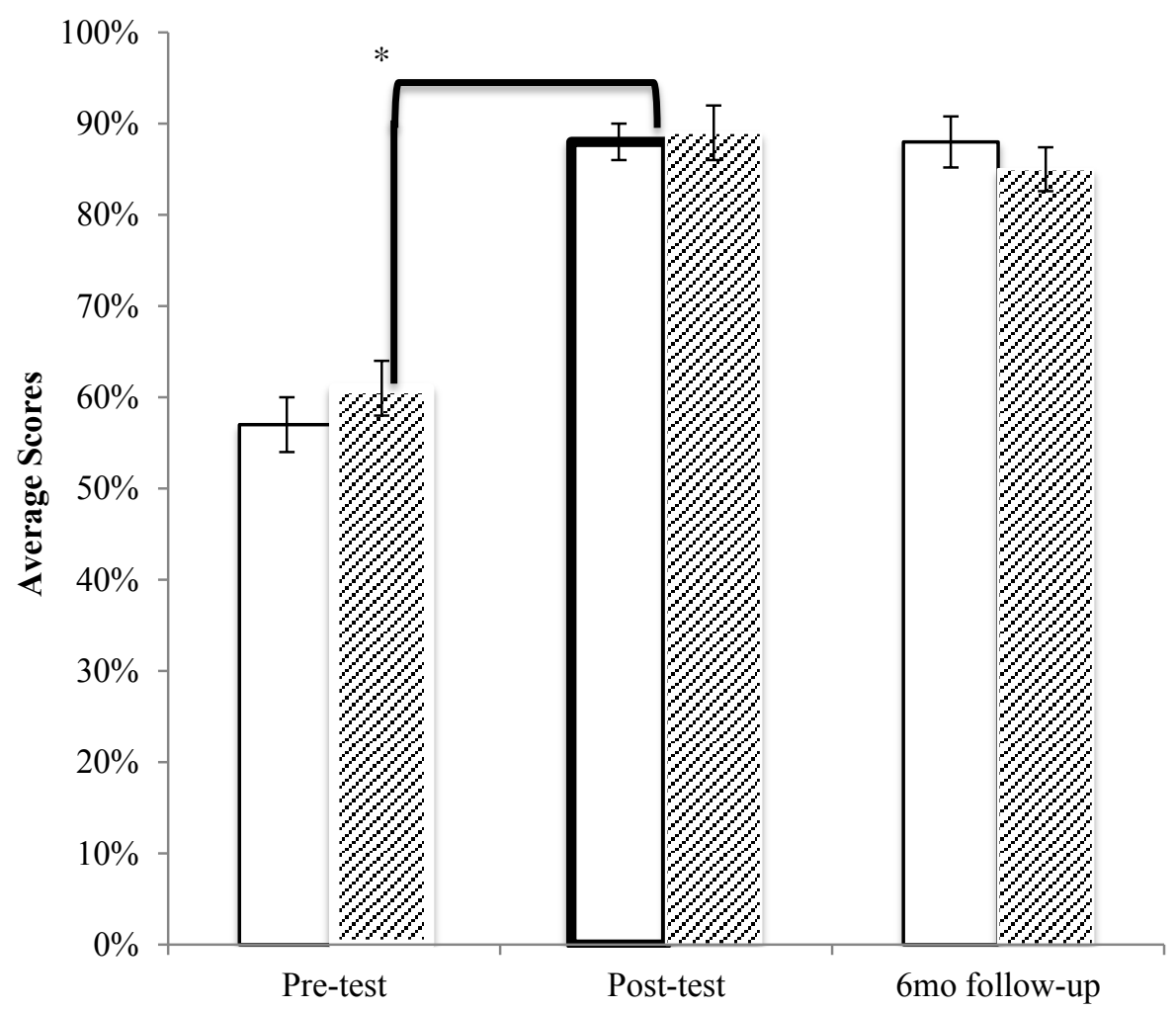

Figure 2. Average percentage scores and standard error of students in group A (white bar) and B (gray bar) in the pre-, post-, and 6-month follow-up tests. There was a statistically significant increase for both groups between pre-test and post-test $(\mathrm{p}=0.0001)$ and pre-test and 6-month follow-up $(\mathrm{p}=0.0001)$. Darker outline shows the comparison immediately after both group received instruction on cardiac cycle for the first time (post-test for group A x pre-test for group B $(\mathrm{p}=0.0000467)$

Both groups were similar in regards to gender, age, highest degree, and previous experience of cardiac cycle physiology before medical school.

Statistical tests for pre-test scores between Group A (57\%) and Group B (61\%) showed no significant difference $(\mathrm{p}=0.60)$, although there was a trend for Group B students to score higher (Figure 2). Students in Group A, who had not received any of the content at all, scored at approximately the same level on the pretest as did students in Group B, who had received a lecture on the content.

The overall scores on the immediate posttest for the two groups were not significantly different (Group A, 88\%; Group $\mathrm{B}, 89 \% ; \mathrm{p}=0.65$ ), even though at the time of the posttest students in Group A had been taught the content based on dramatization alone whereas students in Group B had been taught the content using lecture and dramatization. Students in both groups had higher scores on the immediate posttests in comparison with pretests $(\mathrm{p}<0.0001$, Figure 2$)$. There was a statistically significant difference between the pre-test and immediate posttest for Group A ( $\mathrm{p}$-value $=0.0016$ ), but there was no difference between the immediate posttest and the six-month follow-up test for Group A. There was also a statistically significant difference between the pretest and the immediate posttest for Group B (p-value $=0.0005)$, but no difference between the immediate posttest and the six month follow-up test for Group B.

There was a significant difference between the posttest scores for Group A students and the pretest scores for Group B students $(\mathrm{p}=0.0001)$. This indicates that students who participated in only the dramatization activity scored significantly higher on an immediate test of their knowledge of the cardiac cycle $(88 \%)$ when compared to students who took the same immediate knowledge test after participating only in lecture (61\%) (Figure 2).

Upon 6-month follow-up, students in both groups demonstrated retention of knowledge by achieving the same approximate scores compared to scores at time of pretest ( $\mathrm{p}<0.0001)$. Group A students $(89 \%)$ and Group B students (85\%) showed no significant difference between test scores after a 6 -month period $(\mathrm{p}=0.24)$. Moreover, compared to the immediate after-activity posttest scores, data for the 6-month follow-up tests showed no significant decrease in scores $(\mathrm{p}=0.31)$. Figure 2 displays the percentage average scores in the questionnaire for each group for the pre-test, post-test, and 6-month follow-up test. 
Group A

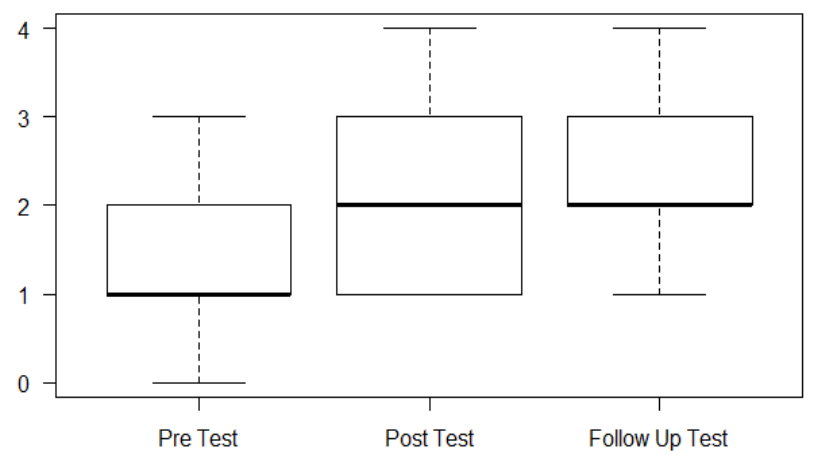

Group B

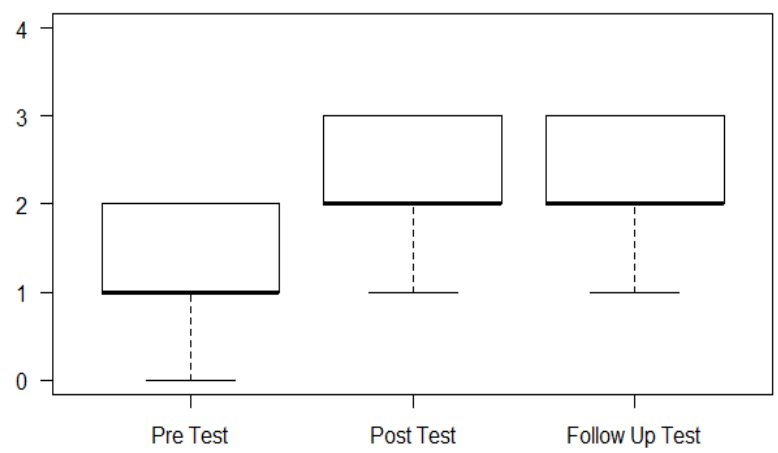

Figure 3. Confidence levels between pre-test, post-test, and 6-month follow-up for groups A and B

When each question was analyzed individually, the number of students who answered each question correctly improved for selected questions. For both groups, questions three through eight yielded significant differences with the odds of correctly answering those questions statistically significantly higher in both immediate posttest and six month follow-up tests, compared with pre-test $(\mathrm{p}<0.05)$. These topics are: Q3: Parasympathetic system at rest; Q4: neurotransmitter involved at rest, Q5: neurotransmitter involved in exercise, Q6: $\beta 1$ receptor activation, Q7: M receptor location, Q8: $\beta$ 1 receptor location.

Students in both groups also rated their confidence level regarding their learning at the time of the pre-test, post-test, and 6-month follow-up assessments (see Figure 3). Frequencies of each of the five categories (insufficient, okay, good, very good, and excellent) were collected and the average confidence levels for all participants were compiled. There was no significant difference between the pretest confidence levels for Groups A and B ( $p$-value=0.84). Also, there was no significant difference between the immediate posttest confidence levels for Groups A and B (p-value=0.6103). For both groups, there was a significant difference in confidence level from the pretest to the immediate posttest. For Group A, average confidence increased from 1.46 to 2.23, and for Group B, average confidence increased from 1.35 to 2.29. There was no significant difference between the immediate posttest confidence levels and the follow-up posttest confidence levels for either group. There was a statistically significant difference between the posttest confidence level of Group A and the pretest confidence level of Group B (0.04822). This means that Group A students were more confident in their knowledge after participating in the drama than were Group B students who experienced lecture alone.

The correlation between student confidence and total scores on the three knowledge tests were as follows (association between total score and student confidence): for Group A_pretest $\mathrm{r}=0.44$ ( $\mathrm{df}=11$, p-value $=0.13$ ); for Group A immediate posttest $\mathrm{r}=0.59(\mathrm{df}=11, \mathrm{p}$-value $=0.035)$; for Group A_follow-up $\mathrm{r}=-0.34(\mathrm{df}=11, \mathrm{p}$-value $=0.25)$; for Group B pretest $\mathrm{r}=0.13(\mathrm{df}=15$, p-value $=0.61)$; for Group B immediate posttest $\mathrm{r}=0.41(\mathrm{df}=11, \mathrm{p}$-value $=0.10)$; for Group B follow-up $\mathrm{r}=0.24 \quad(\mathrm{df}=11, \mathrm{p}$-value $=0.36)$.

In addition, written comments from students showed that they were satisfied with the interactive learning experience, with some stating that they preferred it to traditional lecture. As one student wrote, dramatization was a "fun activity and we learned a lot" and "this [activity] allowed better comprehension and [was] a great break from routine lecture."

\section{Discussion}

This study was designed to test an innovative educational approach that incorporated dramatization into teaching cardiac cycle physiology. This method engages students in active learning and contrasts greatly with more traditional methods of teaching such as giving a lecture.

On a 13-item knowledge pretest pertaining to the cardiac cycle, students in both groups performed equally well even though one group had experienced no teaching at all prior to completing an initial pretest and the other group had experienced a lecture prior to completing the identical pretest. The group that had traditional teaching prior to taking the pretest scored higher, but not significantly higher, on the pretest. This is an interesting finding, especially given the fact that students in the dramatization group reported less prior experience in learning physiology. Several possible explanations for this finding are offered. First, the four point difference in pretest scores between the two student groups may be attributable to random chance as easily as it may be explained by any other factors impacting student knowledge. Second, it is possible that students in Group B simply did not retain sufficient information from the lecture to allow them to outperform students in Group A. This phenomenon was well described in Richardson (Richardson, 2000), who demonstrated that students without previous exposure to formal physiology teaching performed similarly to two other 
groups of experienced students who had already taken a physiology course when testing concepts and their application both in pre- and post-test. According to the author, the low retention of experienced students relates to the passive didactic style of teaching in introductory physiology courses. A third possible explanation is that the pretest instrument itself did not contain questions of sufficient rigor, so that students who took the pretest prior to receiving any teaching about the cardiac cycle were nevertheless able to answer questions equally well as those students who had received teaching about it. Since both student groups scored relatively low on the pretest, this possibility may have less credence but cannot be excluded.

Both groups also performed equally well on the first posttest, even though students in Group A had experienced only dramatization and students in Group B experienced two methods of teaching (lecture and dramatization). This is also an interesting finding, and lends support to the use of dramatization as a potentially powerful teaching method. In our course, dramatization places emphasis not only on learning the factual aspects of the cardiac cycle but also on application of that knowledge. At this stage of our students' medical education, it may be more important to learn how to apply the information than to learn too many specific details without context (Miller et al., 2013). If true, educators need to understand that the content focus should be switched from merely delivering facts to providing opportunity for students to critically reflect on how to apply their knowledge.

Perhaps the most interesting finding from our study, however, pertains to the fact that students who had experienced only dramatization as a teaching method performed better than students who had experienced more traditional teaching methods (lecture) on a knowledge test administered immediately after their initial exposure to the same content, with the only difference being the teaching method used. The difference in these scores was statistically significant and much higher for Group A (dramatization method, 89\% correct) than for Group B (traditional methods, 61\% correct). We interpret this finding as an endorsement of this active learning technique, one that not only appears to be more pleasant and engaging for the students but also resulted (at least in the present study) in a higher level of learning.

We were pleased that all students appeared to retain the material at a high level at the time of the 6-month follow-up posttest. And, we were not surprised that both student groups retained the information equally well at that time, given that all students participated in both types of learning activities. We were not able to truly compare the retention of material by students who only experienced dramatization, as not allowing half of the students to participate in all forms of content delivery would have compromised some of the students' overall learning. Thus, we are left only to speculate about whether students who learn material through dramatization alone would retain the material better than students taught through more traditional methods. Our plans for future studies include delivery of the material via only traditional methods (lecture) and determining the impact of not providing dramatization at all on student performance, as measured by the same 13-item knowledge assessment. This would allow us to examine a similar group of medical students receiving the same content on the cardiac cycle, which would serve as an approximate control group for retrospective comparison.

Regarding student performance on the individual questions in which the odds of answering correctly after dramatization were significant, we find that these questions addressed neurotransmitters and their receptors. This content is something that participants were able to visualize and their consequences were physically acted out. Thus, for topics that students could directly visualize and were addressed physically in the dramatization, students had better odds of providing the correct answers on the assessment. The same topic covered in a lecture setting may not be retained as well as it was through dramatization. In contrast, whereas a lecture can cover a larger amount of material, the nature of a more engaging learning activity (such as dramatization) may not allow enough time to completely cover the same amount of content (Miller et al. 2013). During the dramatization, focus was placed on changes in cardiac dynamics during exercise and the autonomic nervous system response to it. As a result, significantly more students answered correctly when asked about the ANS neurotransmitters regarding exercise vs. rest.

Our data shows that the level of student confidence in their knowledge increased for both groups but increased more dramatically for students who experienced the dramatization method of teaching. We believe that students' confidence increased as they experienced kinesthetic activity and used all senses to engage their memory. Physically engaging activities have been shown to improve student confidence in learning the material by alleviating uncertainty or anxiety (Miller et al. 2013). This improved confidence may have contributed to the increased scores in questionnaires on the immediate post-test and 6-month follow-up post-test.

There are several ways to expand on the use of dramatization for teaching purposes. The first is by learning from mistakes. Any active learning process must be carefully planned and rehearsed in advance. However, when mistakes arise, an interesting aspect of using dramatization for teaching is that these mistakes can be used as teaching opportunities instead of allowing them to turn into misconceptions, which can be difficult to remediate (Morton, Doran, \& Maclaren, 2008). For example, during the dramatization when an individual student moved too early we discussed 
ectopic contractions and the importance of syncytium of cardiac muscle.

This methodology can also be expanded to other areas such as pathology and pharmacology. For instance a pharmaceutical intervention can be portrayed using dramatization by asking a student to act as beta-blocker and 'bind' to the SA node consequently limiting its function. A pathology example is that of ventricular and supraventricular arrhythmias that can be represented by a single or multiple students falling out of sync with the heart's rhythm.

The extra effort required to use a more active teaching methodology must be considered prior to its implementation in the classroom. It is understandable that instructors tend to resist implementing active learning methods (Silverthorn, Thorn, \& Svinicki, 2006) since the development of interactive class sessions is time consuming and many faculty members are comfortable with traditional lectures (Miller et al. , 2013). However, it is necessary to use a variety of teaching methods with emphasis on active learning in order to meet student needs, promote both short and long term knowledge gains and ensure application of knowledge. This multi-method approach will serve to better prepare them for the challenges they will encounter in their professional lives.

In conclusion the use of dramatization as a teaching method appears to have great potential to be both effective and well received by students. Its implementation is essentially free of any costs, making it a practical and interactive method of teaching the cardiac cycle which can be modified or supplemented with other activities. As shown, dramatization can improve understanding, retention of material and satisfaction among medical students.

\section{Acknowledgments}

We thank our former medical students shown in Figure 1: Drs Katie Gambale (as sinoatrial node); Brian Pitts (as atrioventricular node); Sarah Brubaker, Joseph Pechacek; Chris Reed; Russel Trigonis (as Atrial myocytes) and Jaclyn Dovico, Scott Call, Wayne Chang, Andrew Lee, David Reilly, Julia Selfridge (as Ventricle myocytes).

\section{References}

Alkhasawneh, E. (2013). Using VARK to assess changes in learning preferences of nursing students at a public university in jordan: Implications for teaching. Nurse Education Today, 33(12), 1546-1549.

http://dx.doi.org/10.1016/j.nedt.2012.12.017

Breckler, J., \& Yu, J. R. (2011). Student responses to a hands-on kinesthetic lecture activity for learning about the oxygen carrying capacity of blood. Advances in Physiology Education, 35(1), 39-47. http://dx.doi.org/10.1152/advan.00090.2010

Carvalho, H. (2009). Active teaching and learning for a deeper understanding of physiology. Advances in Physiology Education, 33(2), 132-133. http://dx.doi.org/ 10.1152/advan.00024.2009

Carvalho, H., \& West, C. A. (2011). Voluntary participation in an active learning exercise leads to a better understanding of physiology. Advances in Physiology Education, 35(1), 53-58.

http://dx.doi.org/10.1152/advan.00011.2010

Cavanagh M. (2011) Students' experiences of active engagement through cooperative learning activities in lectures. Active Learning in Higher Education, 12, 23-33. http://dx.doi.org/10.1177/1469787410387724

DiCarlo, S. E. (2009). Too much content, not enough thinking, and too little FUN. Advances in Physiology Education, 33(4), 257-264. http://dx.doi.org/10.1152/advan.00075.2009

Freeman, S., Eddy, S. L., McDonough, M., Smith, M. K., Okoroafor, N., Jordt, H., \& Wenderoth, M. P. (2014). Active learning increases student performance in science, engineering, and mathematics. Proceedings of the National Academy of Sciences, 111(23), 8410-8415. http://dx.doi.org/10.1073/pnas.1319030111

Giffen, Z. C., \& Carvalho, H. (2015). Development of a manipulative for nephron physiology education. Advances in Physiology Education, 39(1), 39-41. http://dx.doi.org/10.1152/advan.00087.2013

LePard, K. J. (2005). Student demonstration of relationship between intestinal slow waves and phasic contractions. Advances in Physiology Education, 29(2), 131-132. http://dx.doi.org/10.1152/advan.00011.2005

Lilienfield, L. S., \& Broering, N. C. (1994). Computers as teachers: Learning from animations. The American Journal of Physiology, 266(6 Pt 3), S47-54. Retrieved from

https://www.researchgate.net/publication/15180764_Computers_as_teachers_Learning_from_animations

Lujan, H. L., \& DiCarlo, S. E. (2006a). First-year medical students prefer multiple learning styles. Advances in Physiology Education, 30(1), 13-16. http://dx.doi.org/10.1152/advan.00045.2005

Lujan, H. L., \& DiCarlo, S. E. (2006b). Too much teaching, not enough learning: What is the solution? Advances in Physiology Education, 30(1), 17-22. http://dx.doi.org/10.1152/advan.00061.2005 
Michael, J., Modell, H., McFarland, J., \& Cliff, W. (2009). The "core principles" of physiology: What should students understand? Advances in Physiology Education, 33(1), 10-16. http://dx.doi.org/10.1152/advan.90139.2008

Miller, C. J., McNear, J., \& Metz, M. J. (2013). A comparison of traditional and engaging lecture methods in a large, professional-level course. Advances in Physiology Education, 37(4), 347-355. http://dx.doi.org/10.1152/advan.00050.2013

Montrezor, L. H. (2014). The synaptic challenge. Advances in Physiology Education, 38(2), 187-190. http://dx.doi.org/10.1152/advan.00145.2013

Morton, J. P., Doran, D. A., \& Don P. M. M. (2008). Common student misconceptions in exercise physiology and biochemistry. Advances in Physiology Education, 32(2), 142-146. http://dx.doi.org/10.1152/advan.00095.2007

Prunuske, A. J., Batzli, J., Howell, E., \& Miller, S. (2012). Using online lectures to make time for active learning. Genetics, 192(1), 67-72. http://dx.doi.org/10.1534/genetics.112.141754

Richardson, D. R. (2000). comparison of naive and experienced students of elementary physiology on performance in an advanced course. Advances in Physiology Education, 23(1), 91. Retrieved from http://www.ncbi.nlm.nih.gov/pubmed/10902532

Shenoy, N., Shenoy, K. A., \& U, P. R. (2013). The perceptual preferences in learning among dental students in clinical subjects. Journal of Clinical and Diagnostic Research: JCDR, 7(8), 1683-1685. http://dx.doi.org/10.7860/JCDR/2013/4940.3219

Silverthorn, D. U., Thorn, P. M., \& Svinicki, M. D. (2006). It's difficult to change the way we teach: Lessons from the integrative themes in physiology curriculum module project. Advances in Physiology Education, 30(4), 204-214. http://dx.doi.org/10.1152/advan.00064.2006

This work is licensed under a Creative Commons Attribution 3.0 License. 